
Alhaji MA
Akuhwa RT
Mustapha MG
Ashir GM
Mava Y
Elechi HA
Bukar FL

\section{Post-neonatal tetanus in University of Maiduguri Teaching Hospital, North-eastern Nigeria}

DOI:http://dx.doi.org/10.4314/njp.v40i2,9

Accepted: 24th August 2012

Alhaji MA ( $)$

Akuhwa RT, Mustapha MG, Ashir GM

Mava Y, Elechi HA

Department of Paediatrics,

University of Maiduguri Teaching

Hospital,

P.M.B. 1414, Maiduguri,

Borno State - Nigeria.

Email: m_alhaji@hotmail.com

Tel: +2348065703378

Bukar FL

Department of Community Medicine,

College of Medical Sciences,

University of Maiduguri,

PMB 1069, Maiduguri,

Borno State - Nigeria.

\begin{abstract}
Background: Tetanus is a public health problem in Nigeria. This study examines the demographic and clinical profile of postneonatal tetanus (PNT) seen in University of Maiduguri Teaching Hospital (UMTH), North- eastern Nigeria.

Methods: This is a hospital-based prospective study of PNT. All children beyond the neonatal period to 14 years of age admitted into the Paediatrics unit of UMTH, Maiduguri from June 2009 to July 2011 with the diagnosis of PNT were studied.

Results: A total of 39 cases of PNT were admitted over the period under review. The male: female ratio was 2.3:1.0. Their ages at presentation ranged between 16 months and 14 years, with mean \pm SD of $6.9 \pm$ 3.87 years. Over 90 percent of the children were either not immunized against tetanus or their immunization status was unknown and only two of the children were fully
\end{abstract}

immunized. No booster immunization was received by any of the eligible children. The portal of entry of the infection was injury to the lower limbs and otogenic route in $53.9 \%$ and $33.3 \%$ respectively. Majority of patients were of low socioeconomic status. The duration of hospital stay ranged between 1-50 days with mean \pm SD (18.68+ 11.51). The mortality rate was (7) $18 \%$.

Conclusion: Tetanus still remains a major cause of childhood morbidity and mortality in Nigeria. Severe disease and the first one week of admission are the main variables identified to influence outcome. Therefore, there is need to strengthen routine immunization and booster doses of tetanus toxoid (TT) should be mandatory at primary and secondary school entry. Close monitoring of patients with severe tetanus during the critical period is imperative for successful management.

\section{Introduction}

Tetanus is prevalent with high morbidity and mortality in developing countries of Africa and Asia, including Nigeria. ${ }^{1-7}$ Tetanus is the seventh childhood killer disease in Central African Republic. ${ }^{8}$ Three and half decades after the adoption of Expanded Programme on Immunization (EPI) in Nigeria, tetanus still remains a public health problem unlike in the developed countries. ${ }^{9}$ Reasons attributed to high burden of the disease in Nigeria and other developing countries include low immunization coverage, lack of sustainability of immunization programmes and deficient booster doses of tetanus toxoid at appropriate period to eligible children. ${ }^{4,5,10}$ Tetanus is a vaccine preventable disease caused by Clostridium tetani.
A study of all cases of post-neonatal tetanus (PNT) managed at the University of Maiduguri Teaching Hospital (UMTH) was conducted to highlight factors associated with acquisition of this preventable disease, document the clinical profile and outcome in our environment, and proffer possible suggestions on reducing or eliminating the disease.

\section{Materials and Methods}

All cases of post-neonatal tetanus admitted into the Paediatrics unit of the UMTH over 2 year period, June 2009 to July 2011 were consecutively enrolled into the study. 
Post-neonatal patients with diagnosis of tetanus were admitted into the Emergency Paediatrics Unit (EPU) first, and subsequently transferred to Paediatric Medical Ward (PMW) when stable and nursed in a quiet room with minimal stimulation.

Information obtained at presentation include age, sex, date of admission, immunization status, social background of the patients using Oyedeji's classification. ${ }^{11}$ Associated morbidity/complications and the duration of hospital stay, and outcome were also documented.

The diagnosis of tetanus was clinical, based on the disease characteristic features. ${ }^{12}$

Permission to conduct the study was obtained from the Research and Ethical Committee of UMTH.

Disease classification into mild, moderate, and severe was based on the presence of trismus, risus sardonicus, but no spasm; presence of minimal provoked spasms; and sustained and spontaneous spasms and or opisthotonus, respectively. ${ }^{13}$

Each patient was managed with the use of anti-tetanus serum (ATS) for passive immunotherapy to neutralize the toxins, sedation and spasms control with drug combination therapy; phenobarbitone, chlorpromazine, and diazepam, given parenterally, until spasms were fully controlled before changing to oral. Breakthrough spasms, defined as spasms occurring after initial control of spasms, were treated with diazepam. Antibiotics, including procaine penicillin or metronidazole were given to eradicate organisms. Nutrition was maintained with high protein pap, given by naso-gastric tube feeding, until patients could tolerate orally. With severe spasms, intravenous fluids were administered until spasms subsided before commencing feeding. Tetanus toxoid (TT) was also given to all patients for active immunization before discharge.

Data obtained were analysed using SPSS version 11.0 (Chicago, Illinois, USA). Comparisons between categorical variables were done with appropriate Chi-square $\left(x^{2}\right)$ test. A p-value of $<0.05$ was considered significant. Tables were used for data presentation where necessary.

\section{Results}

There were 39 cases of PNT out of the total of 2814 admissions into the Paediatric unit over the two year study period, accounting for an incidence of $1.4 \%$. There were 27 males and 12 females, giving a male: female ratio of 2.3: 1.0. Their ages ranged between 16 months and 14 years, with mean \pm SD of $6.9 \pm 3.87$. Fifteen $(38.5 \%)$ of the children were under 5 years. Only $2(5 \%)$ of the patients were fully immunized and none of the 18 eligible children received booster doses of tetanus toxoid. Generalised tetanus was seen in 38(97.4\%) cases while localised tetanus was documented in only $1(2.6 \%)$ case which involved the left lower limb, following intramuscular injection to the left gluteal region for a febrile illness. Lower limb injury was the commonest portal of entry in $21(53.9 \%)$ of the cases, while suppurative otitis media (SOM) was documented in $13(33.3 \%)$ of the cases. There was no documented case of traditional circumcision or uvulectomy as a portal of entry in this study. The duration of hospital stay ranged between a day and 50 days, with mean \pm SD $(18.68 \pm 11.51)$. Information on socio-economic class showed that only one $(2.6 \%)$ patient each were in the socio-economic class I and 11 , while $7(17.9 \%), 8(20.5 \%)$, and $22(56.4 \%)$ of the children were from the socio-economic classes III, $\mathrm{IV}$, and $\mathrm{V}$, respectively.

Table 1 shows demographic and the clinical profile of the patients studied.

Table 1: Demographic and clinical profile of the study population.

Age distribution

Number of cases $(\%)$

\begin{tabular}{lll}
\hline Less than 5 years & 15 & 38.5 \\
5-10 years & 16 & 41.0 \\
Above 10 years & 8 & 20.5 \\
Gender distribution & & \\
Male & 27 & 69.2 \\
Female & 12 & 30.8 \\
Immunization status & & \\
Fully immunized & 2 & 5.0 \\
Unimmunized & 22 & 56.4 \\
Uncertain/unknown & 15 & 36.1 \\
Incomplete/partial immunization & 1 & 2.5 \\
Portals of entry of infection & & \\
Injuries to lower limbs & 21 & 53.9 \\
Suppurative otitis media & 13 & 33.3 \\
Unidentified & 4 & 10.3 \\
Others & 1 & 2.5 \\
Duration of hospital stay & & \\
< 1 week & 3 & 7.7 \\
1-2 weeks & 16 & 41.0 \\
3-4 weeks & 14 & 35.9 \\
> 4 weeks & 6 & 15.4 \\
Outcome & & \\
Discharged & 30 & 77.0 \\
Left against medical advice & 2 & 5.0 \\
Died & 7 & 18.0 \\
\hline
\end{tabular}

Twenty $(51.3 \%)$ of the children had identified comorbidities which include: bronchopneumonia (10), malaria (9), and measles (1). Of the 20 children with comorbidities, six (30\%) had multiple co-morbidities. The overall mortality was seven (18\%). Six $(86 \%)$ each of the mortality cases had severe disease at presentation and died within one week of admission respectively. All the mortality cases except one patient were in the low social class. Lower limb injuries and otogenic route, as portals of entry were significantly observed in school age ( $\geq 5$ years) and pre-school age $(<5$ years) respectively $(\mathrm{p}=0.00013)$. There was no statistical relationship observed between mortality and variables such as age, incubation period, period of onset, and portal of entry as shown in table 2 . 


\begin{tabular}{|c|c|c|c|c|}
\hline Variables & & Outcome & & p-value \\
\hline Age & Died & Survived & Lama & \\
\hline$<5$ years & 2 & 5 & 0 & $* 0.44$ \\
\hline$\geq 5$ years & 13 & 17 & 2 & \\
\hline \multicolumn{5}{|c|}{ Incubation period (days) } \\
\hline$<7$ & 2 & 10 & 1 & $* 0.50$ \\
\hline $7-14$ & 1 & 4 & 0 & \\
\hline$>14$ & 0 & 6 & 1 & \\
\hline Unknown & 4 & 10 & 0 & \\
\hline \multicolumn{5}{|c|}{ Period of onset (days) } \\
\hline$<3$ & 2 & 8 & 1 & $* 0.63$ \\
\hline $3-7$ & 2 & 4 & 0 & \\
\hline$>7$ & 0 & 6 & 1 & \\
\hline Unknown & 3 & 12 & 0 & \\
\hline \multicolumn{5}{|l|}{ Portal of entry } \\
\hline Lower limb injury & 3 & 15 & 1 & $* 0.65$ \\
\hline SOM & 2 & 11 & 4 & \\
\hline Others & 2 & 4 & 0 & \\
\hline
\end{tabular}

SOM = Suppurative Otitis Media

Lama $=$ Left against medical advice

* Fisher exact test

\section{Discussion}

This study reveals that post-neonatal tetanus is still prevalent in our environment despite the availability of effective vaccines. Thirty nine cases of PNT reported in this study in 2 years were higher than the 12 cases of PNT over 4 year period reported by Bondi and Alhaji ${ }^{14}$ in the same centre, 2 decades ago. This could be explained by the fact that, there was an intense immunization against the six killer diseases including tetanus, with high immunization coverage in Borno State (19881991) and apparent reduction in morbidity from the disease. However, the immunization programme was not sustained due to ineffective primary health care services and lack of political will among others. This led to resurgence of vaccine preventable diseases, including tetanus, in Nigeria as earlier reported. ${ }^{5,15}$ In many parts of Northern Nigeria, the study centre inclusive, only about 10 percent of children receive all of their routine vaccines. $^{16}$

The preponderance of tetanus among the school aged and in males is in consonance with other reports from Nigeria. ${ }^{1,4,5,10}$ This could be attributed to their exploratory nature which exposes them to injury and thus, causal organism, C. tetani. Another reason could be due to lack of protective footwear among school children that predisposes then to penetrating injuries as most of the cases had lower limb injury as portal of entry.

Majority of the children were unimmunized, which is similar to reports by other workers. ${ }^{1-7.15-17}$ Two of the patients that were fully immunized in infancy developed tetanus, similar to reports by Nte $e t a l,{ }^{3}$ Anah et $a l,{ }^{5}$ and Fatunde et $a l .{ }^{10} \mathrm{~A}$ possible explanation include waning of the protective levels of neutralizing antibodies in older children especially, if booster doses of tetanus toxoid were not given, as is the case in these two children. Although lack of immunization is the greatest risk factor for tetanus in susceptible individuals, vaccination with tetanus toxoid does not confer 100 percent protection against tetanus. ${ }^{18}$

Majority $(61.5 \%)$ of the subjects were aged five years and above, and hence, eligible for booster doses of TT, but none had one, consistent with previous findings. ${ }^{1,4,10}$ The major portals of entry identified in this study were injury to the lower limbs, followed by the otogenic route of the infection which agrees with findings from other studies. ${ }^{1,3,17}$

The mean duration of hospitalization of 18.68 \pm 11.51days ( range of 1-50 days) is comparable to the report from Calabar, Nigeria. ${ }^{5}$ Prolonged duration of hospital stay has a negative impact on hospital resources as well as an increased cost of health care for the family in addition to social burden. This was seen in one of the patients whose parents left against medical advice because of increasing cost of health care and social pressure. Most of the patients in this study were from lower social classes, similar to reports by Akuhwa et $a l^{1}$ and Adegboye et $a l .{ }^{17}$ This has been attributed to the interplay of ignorance, poverty and infection which is often seen among the low social class. The influence of socioeconomic and cultural factors in health and certain diseases has been highlighted. ${ }^{19}$

Bronchopneumonia being a predominant co-morbidity with fatal outcome in patients with tetanus has been reported.$^{20}$ It could be due to restrictive defect from muscular rigidity and spasms of the chest wall, poor cough and increased bronchial secretions resulting in atelectasis with secondary bacterial infection or due to aspiration pneumonia. ${ }^{20}$

The influence of the severity of the disease at presentation on outcome in this study is similar to reports by Anah et al. ${ }^{5}$ This could be attributed to airways obstruction from laryngospasm, bronchial secretions and autonomic dysfunctions. Most of the patients died within the first week of admission and therefore, is a critical period for patient care in order to minimize the risk of death. Cook et $a l^{20}$ have earlier reported that mortality due to tetanus occurs soon after admission from acute complications such as airways obstruction among others.

The observation that the predominant portals of entry among children beyond 5 years of age and the underfive children as the lower limb injury and SOM respectively is in agreement with previous report. ${ }^{1}$ This may be attributed to the fact that the older children are more predisposed to lower limb injuries from their adventurous nature, whereas, acute respiratory infections is more common among the under-fives that makes them susceptible to SOM.

The overall mortality in this study is comparable to previous study ${ }^{5}$ but lower than the report by Adegboye et $a l^{17}$ with case fatality rate of 62.1 percent. The variance may be due to the fact that, the later study included both neonatal and post-neonatal tetanus.

A similar lack of significant statistical difference noted in the outcome of the under-fives and older children was earlier reported by Mondal et al. ${ }^{7}$ 
The findings in this study that both incubation period and period of onset were not related to outcome, sharply contrast with established literature ${ }^{20}$ and previous studies ${ }^{22,23}$ especially in neonatal tetanus, that both variables correlates inversely to outcome. The reason for these inconsistent findings is not clear but could be due to small study population to deduce a more meaningful statistical inference.

The risk of death had no relationship to the portals of entry of the infection in this study, a finding previously reported by Yadav et al, ${ }^{2 l}$ which implies that site of wound or injury does not influence the severity and prognosis of tetanus.

Tetanus remains a major public health problem in Nigeria and contributes to considerable morbidity and mortality of children. Severe disease and the first one week of admission are the main determinants of outcome, and therefore, extra attention should be paid to these patients, especially during this critical period of admission in order to minimize the risk of death.
It is therefore suggested that health education on immunization be intensified and the inclusion of booster doses of TT at primary and secondary school entry to the NPI schedules as earlier proposed by other workers. ${ }^{7,10}$

Contribution to Authors: The corresponding author conceived the idea and together with all the co-authors was involved in data collection, data analysis and writing of the manuscript. Conflict of interest: None. Funding: None.

\section{Reference}

1. RT Akuhwa, MA Alhaji, MA Bello, SG Bulus. Post-neonatal tetanus in Nguru, Yobe State, Northeastern Nigeria. Nig Med Pract 2010; 51(3): 40-42.

2. MA Alhaji, MG Mustapha, GM Ashir, RT Akuhwa, MA Bello, AG Farouk. Recurrent generalised tetanus: a case report. Trop Doct 2011; 41: 127-128.

3. Nte AR, Mayuku A, Oruamobo RS. Neonatal and post neonatal tetanus: the time to act is now. Nig J Paediatr 2002; 29: 85.

4. Gbadegesin RA, Adeyemo AA, Osinusi K. Childhood postneonatal tetanus. Nig J Paediatr 1996; 23 (1): $11-15$.

5. Anah MU, Etuk IS, Ikpeme OE, Ntia HU, Ineji EO, Archibong RB. Post-neonatal tetanus in Calabar, Nigeria: A 10 year review. Nig Med Pract 2008; 54 (2): 45 - 47.

6. K Mishra, S Basu, Kumar D, AK Dutta, P Kumar, B Rath. Tetanus still a scourge in the $21^{\text {st }}$ century: a paediatric hospital-based study in India. Trop Doct 2012; 42(3):1579.

7. T Mondal, S Aneja, A Tyagi, $\mathrm{P}$ Kumar, D Sharma. A study of childhood tetanus in post-neonatal age group in Delhi. Indian Pediatr 1994; 31: 1369-72.

8. United Nations Children's Fund Report 29 January 2008.

9. Sanford JP. Tetanus - Forgotten but not gone. N Engl J Med 1995; 332:812-3.
10. Fatunde OJ, Familusi JB. Postneonatal tetanus in Nigeria: The need for booster doses of tetanus toxoid. Nig J Paediatr 2001; 28 (2): 35 - 38 .

11. Oyedeji GA. Socio-economic and cultural background of hospitalized children in Ilesha. Nig J Paediatr 1995; 12 (4): 111-7.

12. Menkes JH. Toxic and nutritional disorders. In: Menkes JH, Sarnat HB, Maria BL (eds). Child neurology. $7^{\text {th }}$ ed, 2006; Lippincott Williams \& Wilkins (pubs): pg 703 738.

13. Ablett JL. Analysis and main experiences in 82 patients treated in the Leeds Tetanus Unit. In: Ellis M, ed. Symposium on Tetanus in Great Britain. Boston Spa, UK: National Lending Library, 1967; 1 -10 .

14. FS Bondi, MA Alhaji. The EPI in Borno State, Nigeria: impact on routine disease notifications and hospital admissions. J Trop Med Hyg 1992; 95 (6):373 - 381.

15. AI Lagunju, FO Akinbami, BO Ogunbosi. Childhood tetanus in the post-neonatal age group in Ibadan, Nigeria: Any way nearer eradication? Arch Ibad Med 2008; 9(1\&2):39-41.

16. Abdulkarim AA, Ibrahim RM, Fawi AO, Adebayo OA, Johnson A'WBR. Vaccines and immunization: the past, present and future in Nigeria. Nig J Paediatr 2011; 38 (4): 186-194.
17. Adegboye OA, Adeboye MAN, Anoba S. Childhood tetanus; still a public health concern: A review of 95 cases. Savannah Journal of Medical Research and Practice 2012; 1(1): 20-24.

18. Vinson DR. tetanus: not $100 \%$ preventable (Letter). $J$ Emerg med 1999; 17(4): 745-747.

19. Ebrahim GJ. Social and cultural factors in health. In: Paediatric practice in developing countries. Ebrahim GJ, ed. London: Macmillan Press Ltd 1981: 16-30.

20. TM Cook, RT Protheroe, JM Handel. Tetanus: a review of the literature. Br J Anaesth 2001; 87: 47787.

21. YR Yadav, PC Kala, S Yadav. Study of site and nature of injury as prognosis factors in tetanus. Trop Doct 1990; 20: 136-137.

22. RS Oruamabo, LT Mbuagbaw. Neonatal tetanus in Port Harcourt. Nig J Paediatr 1986; 13 (4):11520.

23. Osinusi K, Njinyam MN. A new prognostic scoring system in neonatal tetanus. Afri J Med Sci 1997; 26: $123-125$. 